\title{
Nutrition education for the elderly
}

\section{By Louise Davies, Geriatric Nutrition Unit, Queen Elizabeth College, London $W 8{ }_{7} A H$}

The extent of the problem of bringing nutrition education to the elderly is partly shown by population statistics: in 1968 , when the Geriatric Nutrition Unit was established, there were about 8.5 million men and women of pensionable age in the UK (i.e. men over 65 and women over 60 ). By 1973, only 5 years later, numbers had risen to 9.3 million. By the year 2001 it is forecast that there will be 9.5 million old age pensioners (Census of Britain, 1971).

In I968 I million were over the age of 80 . The forecast is that this will rise to I. 75 million by 200 I.

Medicine is helping to keep old people alive, although it has not yet come up with the answer to the predominantly male deaths due to heart failure. At the age of 80 the ratio, women:men is $2: 1$, and by 85 years it is $3: 1$. There is therefore an increase in numbers of the elderly in the population, many of them widows living on their own. In the past one could reckon largely on the survival of the fittest. Nowadays many are neither at their fittest nor their happiest. Good nutrition could play an important part in keeping them fitter and happier, and also more independent, so that they could be less of a burden to themselves and, incidentally, to the welfare state.

There will always be the 'elderly élite' (sometimes they are, or claim to be, centenarians). They can adapt their lives, including lifelong food patterns, in spite of physical, psychological and social changes (Watkin, 1968). However, risk factors which can lead to malnutrition in the elderly include loneliness, bereavement, apathy, physical handicap or mental impairment (Exton-Smith, 1970). Moreover, these are people who may not automatically look after, or even question, their diet, because in their day there was no such subject in the school curriculum as nutrition education.

\section{Cookery classes and cookery books for the over-6os}

Over $70 \%$ of the elderly population live in one- or two-person households, not in institutions. Nutrition education can re-arouse their interest in providing nourishing food for themselves. The Geriatric Nutrition Unit was established to provide practical solutions to nutritional problems. One of our first projects was to encourage the setting up of cookery classes for the over-6os throughout the country. These classes have a twofold aim: to teach nourishing, small-scale recipes to often lonely elderly men and women, and at the same time to help them to make social contacts and thus alleviate some of the loneliness and apathy known to be a 
malnutrition risk. They usually meet once a week in the morning, have a talk or demonstration, cook a lunch for one or two and then sit down together to eat what they have cooked. Occasionally a husband or wife will attend, cook for two and take the lunch back to eat in company with the bedridden partner.

A wide range of recipes can be taught even to the physically handicapped. Even the very arthritic can be taught how easy it is to cook with, for instance, the soft margarines which were not available in their youth. There are special classes for the blind and partially sighted, sometimes linked with diabetic recipes, because loss of sight often accompanies diabetes. The Disabled Living Foundation (1 975) has published a cookery book for the disabled and the Gas and Electricity Councils have published details of equipment for the elderly or disabled.

My contribution of recipes and nutrition advice for the elderly was a paperback Easy Cooking for One or Two (Davies, 1975). This was in so much demand that I have been asked to write a companion volume More Easy Cooking for One or Two. It has often been said that food which is not eaten is not nourishing. Therefore nutrition education for the elderly must begin with recipes which are not only nourishing but also acceptable and popular.

An elderly audience is widely varied. One needs very simple meals for the noncook. That includes the widower or the male or female office worker who has never had to cope with cooking until bereaved. The non-cook may also be a good cook who is just too tired or ill that day to be bothered. The elderly audience includes women who have been used to cooking for a family but who lose heart when the family is no more and they try to scale down their recipes. There is also a chapter in my book for the elderly super-cook who wants bread-making or a souffle for one. In contrast there is a chapter for the temporarily or permanently housebound who may need to make up menus from food kept in a store-cupboard.

The Department of Health and Social Security (DHSS) (1972) Nutrition Survey of the Elderly confirmed our findings that old people (with the exception of the very ill) at home, in residential homes and in hospitals do not want special geriatric foods, they do not like industrial catering, they want what we want: good home cooking. In the DHSS (1972) survey, the clinicians found among the 879 elderly subjects 'some but not much overt malnutrition... Nevertheless the survey does show that some old people, even though they may have been only a very small proportion of a sample which included a high proportion of those at special risk, were demonstrably malnourished. There were others for whom more could have been done and others still whose margin of safety must have been narrow. We are certainly not justified in concluding that present services give all the assistance that is required.'

\section{Problems which might be solved with the assistance of nutrition education}

There has been a large number of surveys (Exton-Smith \& Stanton, 1965; Exton-Smith, Stanton \& Windsor, 1972; Corless, Beer, Boucher, Gupta \& Cohen, 1975) pointing to a low vitamin $D$ intake in the elderly, particularly among the housebound and in geriatric wards. When we surveyed too elderly people receiving 
'meals-on-wheels', their intake was even lower than that of the elderly population surveyed by the DHSS (1972). The 'meals-on-wheels' examined were low in food containing vitamin D. Of our sample, $76 \%$ were of limited mobility and $66 \%$ did not even get out to shop for food. When you consider that vitamin D comes from sunlight as well as from only a limited number of foods, these findings give cause for concern. We have prepared (see below) an illustrated lecture on the importance of vitamin $\mathrm{D}$; this is to be shown not only to the elderly but also to those looking after them.

With regard to ascorbic acid, when we analysed the 'meals-on-wheels' we found that instead of the $22 \mathrm{mg}$ expected from the average delivered lunch (by calculation from food composition tables (DHSS, personal communication)), analysis showed only $9 \mathrm{mg}$ (Davies, Hastrop \& Bender, 1973a). Most of the loss was unavoidable because of the long delays between cooking and consumption. However, some of it was due to bad cooking practices and lack of the foods which could have contributed ascorbic acid. We are planning a book of large-scale recipes and nutritional advice for those who cater for the elderly.

The lower limit of normal potassium intake for elderly subjects is stated to be $60 \mathrm{mmol}(2.3 \mathrm{~g}) / \mathrm{d}$ (Judge \& Cowan, 1971). We found that $69 \%$ of our 'meals-onwheels' recipients had a $\mathrm{K}$ intake below this. Low $\mathrm{K}$ has been linked with depression (Dall \& Gardiner, 197I). We asked our investigators to give a subjective assessment of depression after visiting the subject regularly for I week. There was a significant correlation between depression and low $\mathrm{K}$ intake (Davies, Hastrop \& Bender, $1973 b$ ). Of thirty-five subjects considered depressed, twenty had a low $\mathrm{K}$ intake; of sixty-five subjects assessed as not depressed, fifty-three had a higher range of $\mathrm{K}$ intakes.

It may be that the subjects assessed as depressed were getting little $\mathrm{K}$ because they were so depressed that they were eating very little, or turning to the cheap, easy, high-sugar, low- $\mathrm{K}$ foods; or it may be that the lack of $\mathrm{K}$ was causing the depression. This is a field for further research. Meanwhile the message of the Geriatric Nutrition Unit to health visitors, home helps and doctors was: if you see depression or lack of interest in food in elderly patients persuade them to take the simple, high-K foods like milky coffee, milky Marmite, a chocolate milk drink, orange juice or even an easy-to-eat banana.

The emphasis must be made that nutrition education for the elderly must include nutrition education for those looking after them: the home helps, the health visitors, cooks and their supervisors and the doctors.

\section{Cartoon slide lecture kits}

The DHSS (1972) Nutrition Survey of the Elderly made the recommendation that "health education for and about the elderly be extended as an important preventive measure'. This gave the impetus to one of the most challenging projects of the Geriatric Nutrition Unit. Our answer was health education and nutrition education by means of cartoon slide lecture kits: serious lecture notes for the 
lecturer, light-hearted cartoon slides illustrating the points made by the lecturer, and reminder leaflets for the audience to take away.

There are some academics who feel that this is a rather frivolous approach, but let us consider the audience and the conditions under which they would be learning. Most of them are elderly, meeting in the crowded, rather noisy atmosphere of Darby-and-Joan Clubs or day centres; not able, or willing, to concentrate for long; far happier talking than listening. We decided to provide nutrition education which would encourage them to interrupt, ask questions, relax and to identify with the situations depicted. Hundreds of these slide lecture kits have been sold to local authorities, clubs and teachers all over the country (Geriatric Nutrition Unit, Queen Elizabeth College, London W8 $7 \mathrm{AH}$ ).

Sets of slides illustrating the following lectures are available.

\section{Set A: 'An emergency food store for the elderly'}

In a survey undertaken by the Geriatric Nutrition Unit the investigators were dismayed to see how many old age pensioners kept no emergency stocks of food in the house. It only needed bad weather, a temporary illness, a cancelled visit from the home help or neighbour to leave these people housebound without any means of making a meal. We provide twelve colour cartoon slides and leaflets for the audience showing a list of store-cupboard foods from which they can choose.

\section{Set B: 'Keeping foods fresh without a refrigerator'}

When we interviewed old age pensioners for a diet survey we found that $78 \%$ of them did not possess a refrigerator and many were storing foods in a dangerous or wasteful fashion. We are worried about the risk of food-poisoning and waste of food with poor storage conditions, particularly as old people are advised to keep their rooms warm, and often there is no cool larder. We provide twenty-three black-and-white cartoon slides and two leaflets for the audience, (I) Keeping foods fresh, and (2) How to store leftovers.

\section{Set $C$ : 'What is a balanced diet?'}

The theme of the circus has been used to illustrate balance, and the accompanying set of lecture notes are designed for a $15 \mathrm{~min}$ talk, or a shorter talk can be extracted if desired. We have not attempted to dictate set menus but rather to open up the subject to group discussion on what the audience actually eats. An illustrated leaflet for the audience emphasizes the main points of the talk.

The next set of cartoon slides (in preparation) will be called 'Vitamin $D$ and calcium'.

All the lectures illustrate foods and recipes as well as basic nutritional information. In my opinion no nutritionist, no dietitian, no food technologist should be considered sufficiently qualified unless he or she has a sound working knowledge of cookery. It is useless for the technologist to perform marvels in the production of synthetic foods unless he has a clear understanding of the flavour, 
texture and appearance of the final dish. It is useless for the nutritionist to quote in micrograms, megajoules or similar terms the desirable intake of nutrients unless he can translate this into acceptable foods and cookery methods (and alternative cookery methods) and menus which are practical, taking into account physical and mental condition. I am appalled at the number of diet sheets misunderstood or lost in a drawer because there has been no communication in practical terms.

Among the messages in our 'Balanced diet' lecture is 'Keep food cranks at bay'. This message is essential for the elderly. Their main fear seems to be future illhealth and enforced dependance on others. They feel their energy flagging and search for the elixir of life: could it be in honey, vitamin pills or health foods? They are a sitting target for advertisers. They read the newspaper headlines and write to me: 'I understand cholesterol may be bad for my 80-year-old husband so I have persuaded him not to have his usual egg and bacon for breakfast'. This worry and self-imposed diets caused by uninformed publicity is nutrition education for the elderly at its worst.

\section{Other sources of nutrition education}

Apart from the elderly themselves, there are other people to involve in nutrition education of the elderly. Food manufacturers are being persuaded to produce nourishing, acceptable food in small packs. Many shops have been persuaded to make shopping easier for their elderly customers. A number of food shops are producing informative leaflets and booklets. There is nutrition information on radio and television.

I should like future work of the Geriatric Nutrition Unit to include investigations into the nutritional status of the elderly in geriatric wards. Following biochemical and medical examinations we could investigate the possibility of improving health by alterations in diet. One needs the surveys to find the problems, and nutrition education to help to solve them.

For the elderly receiving large-scale catering, for example in luncheon clubs, residential homes and through 'meals-on-wheels', we hope to produce a book on easy cooking for larger numbers, i.e. ten people, fifty people or more, so that they can enjoy what they want: good home cooking. It is up to us to see that it is nourishing.

\section{REFERENCES}

Census of Britain (1971). Persons of Pensionable Age. London: H.M. Stationery Office. Corless, D., Beer, M., Boucher, B. J., Gupta, S. P. \& Cohen, R. D. (1975). Lancet i, 1404. Dall, J. L. C. \& Gardiner, H. S. (1971). Geront. clin. 13, I19.

Davies, L. (1975). Easy Cooking for One or Two. London: Penguin Handbooks.

Davies, L., Hastrop, K. \& Bender, A. E. (1973a). Mod. Geriat. 3, 390.

Davies, L., Hastrop, K. \& Bender, A. E. (1973b). Mod. Geriat. 3, 482.

Department of Health and Social Security (1972). A Nutrition Survey of the Elderly. London: H.M. Stationery Office.

Disabled Living Foundation (1975). Kitchen Sense. London: Heinemann.

Exton-Smith, A. N. (1970). Nutrition, Lond. 24, 218.

Exton-Smith, A. N. \& Stanton, B. R. (1965). Report of an Investigation into the Dietary of Elderly Women Living Alome. London: King Edward's Hospital Fund. 
Exton-Smith, A. N., Stanton, B. R. \& Windsor, A. C. M. (1972). Nutrition of Housebound Old People, p. 13. London: King Edward's Hospital Fund.

Judge, T. G. \& Cowan, N. R. (1971). Geront. clin. 13, 221.

Watkin, D. M. (I968). In Vitamins in the Elderly, p. 66 [A. N. Exton-Smith and D. C. Scott, editors]. Bristol: John Wright \& Sons Ltd. 